\title{
Using Blue Grama Sod for Range Revegetation
}

WILLIAM J. MCGINNIES AND ALMA M. WILSON

\begin{abstract}
Blue grama (Bouteloua gracilis) is often difficult to establish by direct seeding, but in many cases it can be established on some critical areas by sodding. Best results were obtained by: (1) transplanting the sod early in the season (May or June), (2) cutting the sod about $5 \mathrm{~cm}$ thick and keeping it flat in transit, (3) pre-wetting the sod before cutting if the soil was not already wet, and (4) irrigating the sod immediately after laying and preferably an additional two times during the following week. Establishment depended mainly on development of new adventitious roots which were produced only on recently developed tillers. Sod transplanted in May and June produced the most new adventitious roots; sod transplanted in June and July had the greatest rate of adventitious root elongation; and sod transplanted in June produced the greatest total length of new adventitious roots per sample.
\end{abstract}

Blue grama (Bouteloua gracilis) is often difficult to establish from seed (Bement et al. 1965, Hyder et al. 1971). Seedlings frequently fail to produce adventitious roots and thus are unable to survive (Wilson and Briske 1979). Establishing blue grama from sod holds considerable promise and has a definite place when prompt revegetation of relatively small die-off or blow-out a reas is needed. Sod can be used on sites too raw or steep for conventional seeding and on sites where quick cover is needed to prevent erosion. Sod can also be used for rehabilitation of small disturbed areas, for establishing vegetation on special-use areas such as recreation areas, or for native species landscaping. If sufficient need arises, equipment suitable for harvesting and spreading blue grama sod on a larger scale will undoubtedly be developed.

Results from sodding blue grama have been erratic. Therefore, we established a series of small-plot experiments to determine how to best establish blue grama with sod. One of the experiments is reported here.

\section{Methods}

The experiment was conducted at Central Plains Experimental Range, $19 \mathrm{~km}$ (12 miles) north of Nunn, Colorado. Elevation is $1650 \mathrm{~m}(5400 \mathrm{ft})$. Mean annual precipitation is $31 \mathrm{~cm}$, with $22 \mathrm{~cm}$ falling May through September. Precipitation amounts during the growing season (May through September) for this study were 21, 16,20 , and $39 \mathrm{~cm}$ in 1976, 1977, 1978, and 1979, respectively. Soil on the experimental site is a member of the Ustollic Haplargid subgroup. Native vegetation of the experimental area was shortgrass, with blue grama being the dominant species.

The experimental plots were prepared by thoroughly discing the soil on abandoned dry-farm land. The soil was smoothed by hand raking just prior to placing the sod.

\footnotetext{
Authors are range scientist and plant physiologist, respectively, U.S. Dep. Agr., Agr. Res. Serv., Crops Research Laboratory, Colorado State University, Fort Collins 80523 .

This research involved cooperative investigations of U.S. Dep. Agr., Agr. Res. Serv., Fort Collins, Colo., and the Colorado Agr. Exp. Sta., Fort Collins. Published with approval of the Director of the Colorado Agr. Exp. Sta. as Scientific Series No, 2578.

The authors express their thanks to Dennis $M$. Mueller who assisted in the field work.

Manuscript received August 26, 1980
}

Sod was cut from a native stand of nearly pure blue grama with an oscillating-blade sod cutter of the type commonly used in commercial turf production. Sod was cut in strips approximately 5 $\mathrm{cm}$ deep and $30 \mathrm{~cm}$ wide, and the strips were then cut into lengths of 30 to $37 \mathrm{~cm}$. In earlier trials, it was found that when sod was cut 2 to $3 \mathrm{~cm}$ deep, the sod would break apart when it was lifted; sod cut 5 $\mathrm{cm}$ deep would usually stay together. Our sod cutter would not readily cut deeper than $5 \mathrm{~cm}$. Because blue grama is a bunchgrass, it does not form a sod that can be rolled and handled in the same manner as Kentucky bluegrass (Poa pratensis) sod. The pieces of sod were lifted with a flat-blade shovel and loaded on a flat-bed trailer for transport. The layers of sod were inter-leaved with sheets of hardboard to facilitate handling. If sod layers were not interleaved, the layers were difficult to separate and the sod broke apart when separation was attempted.

The sod was placed in plots $122 \times 122 \mathrm{~cm}(4 \times 4 \mathrm{ft})$ within 1 hour after it had been cut and was firmed with a water-filled lawn roller for good soil contact. Fifteen plots were planted on each planting date; the 15 plots were divided into five replications of three plots each. One plot in each replication received no irrigation or further treatment. The second plot was irrigated with $2 \mathrm{~cm}$ of water immediately after transplanting. The third plot was irrigated with 2 $\mathrm{cm}$ of water immediately after transplanting and two additional waterings of $1.3 \mathrm{~cm}$ each during the following 5 or 6 days. These treatments are designated as 0,1 , and 3 irrigations in this paper. Sod was transplanted on various dates May through August of 1976 and 1977.

Because the sod was difficult to handle and broke apart when the soil was dry, on each of two dates in both 1976 and 1977, part of the area from which the sod was cut was watered with about $2.5 \mathrm{~cm}$ of water the day before cutting. This treatment is called "pre-wet." Success of sod cut from the pre-wet area was compared to similar sod that had been cut from the dry area on approximately the same date.

Soil cores, $12 \mathrm{~cm}$ in diameter and $60 \mathrm{~cm}$ deep, were taken 15 to 17 days after transplanting for four planting dates during 1977. These cores were placed in water and the soil was washed from the roots. Numbers of live tillers and new adventitious roots were determined, and the length of all new adventitious root material was measured. Total length of adventitious roots per core was the sum of main axis lengths of all newly formed adventitious roots. Rate of adventitious root elongation was the length of the longest newly formed adventitious root per core divided by the interval between transplanting and sampling.

Soil moisture was measured gravimetrically on the date of transplanting for the surface $2 \mathrm{~cm}$ in the sod before cutting, and in the top $2 \mathrm{~cm}$ and top $15 \mathrm{~cm}$ of the soil onto which the sod was transplanted. Soil moisture cores were obtained before the sod was laid.

Stand establishment was rated August 31, 1978, and September 6, 1979. Establishment was rated on the basis of the area of the sodded plot that was occupied by living blue grama plants expressed as a percent of the total plot area. 


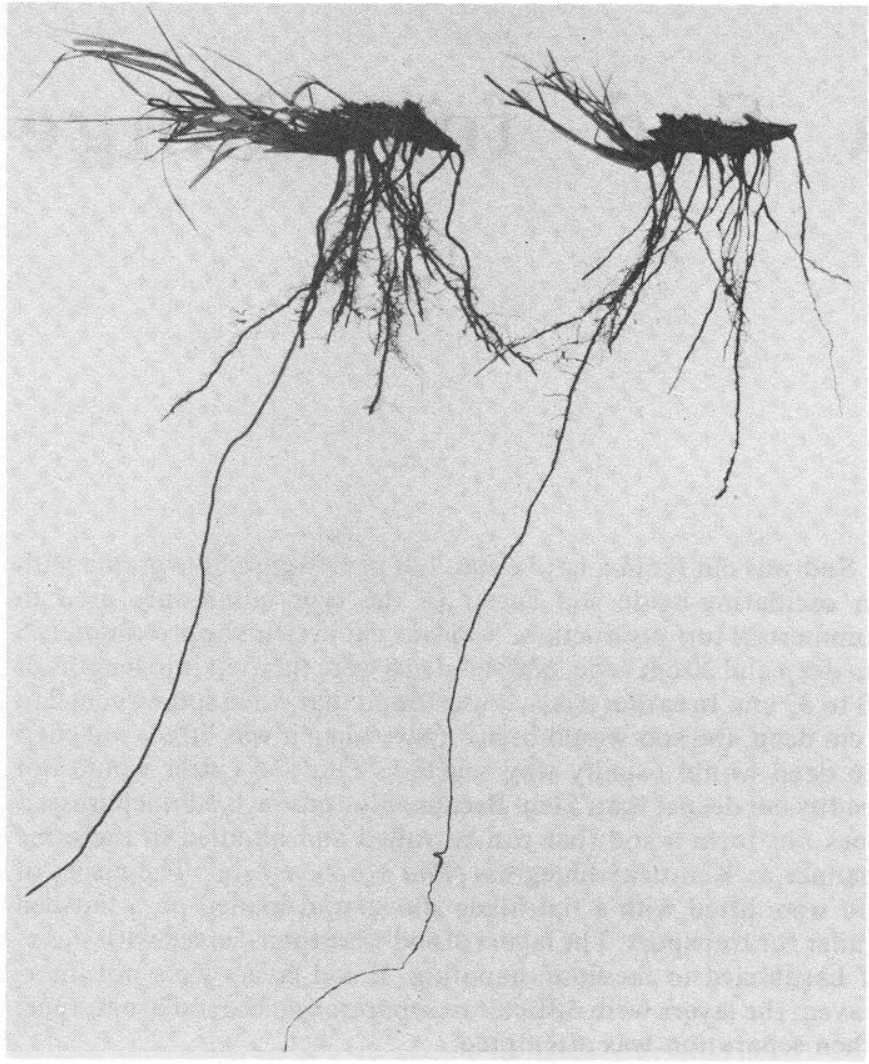

Fig. 1. Development of one adventitious root per tillering sequence in blue grama sod that had been planted May 3, 1977, and then irrigated three times. The adventitious roots, from older portions of the tillering sequence (right), were cut off by the sod-cutter. New adventitious roots generally formed only on the most recently developed tillers.

\section{Results and Discussion}

The date of transplanting and the a mount of irrigation following transplanting are the factors exerting the greatest influence on sod establishment (Table 1). In general, the earlier in the season that the sod was transplanted, the better the results; the correlation coefficient between Julian date and percent stand establishment was -0.74 . During both years, transplanting in May produced excellent stands if the sod was irrigated at least once following transplanting. The date-of-sodding effects appear to be a result of several date-related phenomena such as tiller survival and number of and rate-of-elongation of adventitious roots.

The number of living tillers per 12-cm-diameter core obtained 15 to 17 days after transplanting in 1977 decreased with each succeeding transplanting date (Table 2). In the 0 -irrigation treatment, there were so few surviving tillers at the June, July, and August sampling dates that no sample data were recorded; it was felt that the sample would have been too small to be meaningful.

When the roots were washed out, it was found that new adventitious roots formed only on recently developed tillers (Fig. 1). Thus, if there were no new tillers, no adventitious roots developed. The number of adventitious roots per core decreased as the season progressed and the decrease seemed to be at least partly related to the reduction in tiller numbers (Table 2). The rate of adventitious root elongation reached a maximum in the June-July period. The combined effect of number of roots and rate of elongation was such that the greatest total length per core was produced by the sod transplanted on June 21.

In a very few cases, branch roots developed on cut-off adventitious roots (Fig. 2). These branches occurred on roots from recent tillers. Branch roots were less than half the diameter of other adventitious roots and they did not grow as deeply or as rapidly. Branch roots were more numerous on the June 21 transplanting
Table 1. Percent stand in 1978 and 1979 as affected by date of transplanting sod, number of post-transplanting irrigations, and prewetting sod before cutting.

\begin{tabular}{|c|c|c|c|c|c|c|c|}
\hline \multirow[b]{3}{*}{ Transplanting date } & \multirow[b]{3}{*}{ Pre-wet } & \multicolumn{6}{|c|}{ Number of irrigations } \\
\hline & & \multicolumn{3}{|c|}{1978} & \multicolumn{3}{|c|}{1979} \\
\hline & & 0 & 1 & 3 & 0 & 1 & 3 \\
\hline \multicolumn{8}{|l|}{1976} \\
\hline May 13 & - & 10 & 74 & 82 & 14 & 82 & 84 \\
\hline May 27 & - & 76 & 86 & 90 & 88 & 96 & 92 \\
\hline June 10 & - & 0 & 20 & 24 & 4 & 26 & 38 \\
\hline July $8 * *$ & No & 0 & 10 & 30 & 4 & 8 & 40 \\
\hline July $12^{*}$ & Yes & 24 & 66 & 72 & 32 & 70 & 76 \\
\hline August 3 & - & 8 & 50 & 60 & 12 & 80 & 88 \\
\hline August $18^{*}$ & Yes & 4 & 8 & 26 & 4 & 16 & 60 \\
\hline August $18^{* *}$ & No & 0 & 2 & 10 & 2 & 4 & 10 \\
\hline \multicolumn{8}{|l|}{1977} \\
\hline May 3 & - & 50 & 68 & 84 & 75 & 88 & 90 \\
\hline May 23 & - & 10 & 72 & 76 & 22 & 88 & 90 \\
\hline June $21^{*}$ & Yes & 2 & 28 & 70 & 4 & 58 & 90 \\
\hline June $22 * *$ & No & 2 & 4 & 8 & 0 & 6 & 12 \\
\hline July 27 & - & 0 & 16 & 26 & 6 & 36 & 68 \\
\hline August $23^{*}$ & Yes & 0 & 10 & 18 & 0 & 14 & 40 \\
\hline August 24* & No & 2 & 0 & 4 & 2 & 2 & 4 \\
\hline Average $^{1}$ & Yes & 8 & 28 & 46 & 10 & 40 & 66 \\
\hline Average $^{2}$ & No & 1 & 4 & 13 & 2 & 5 & 16 \\
\hline
\end{tabular}

'Average of those dates (followed by one asterisk) on which sod was pre-wet before cutting.

${ }^{2}$ Average of those dates (followed by two asterisks) on which sod was not pre-wet before cutting.

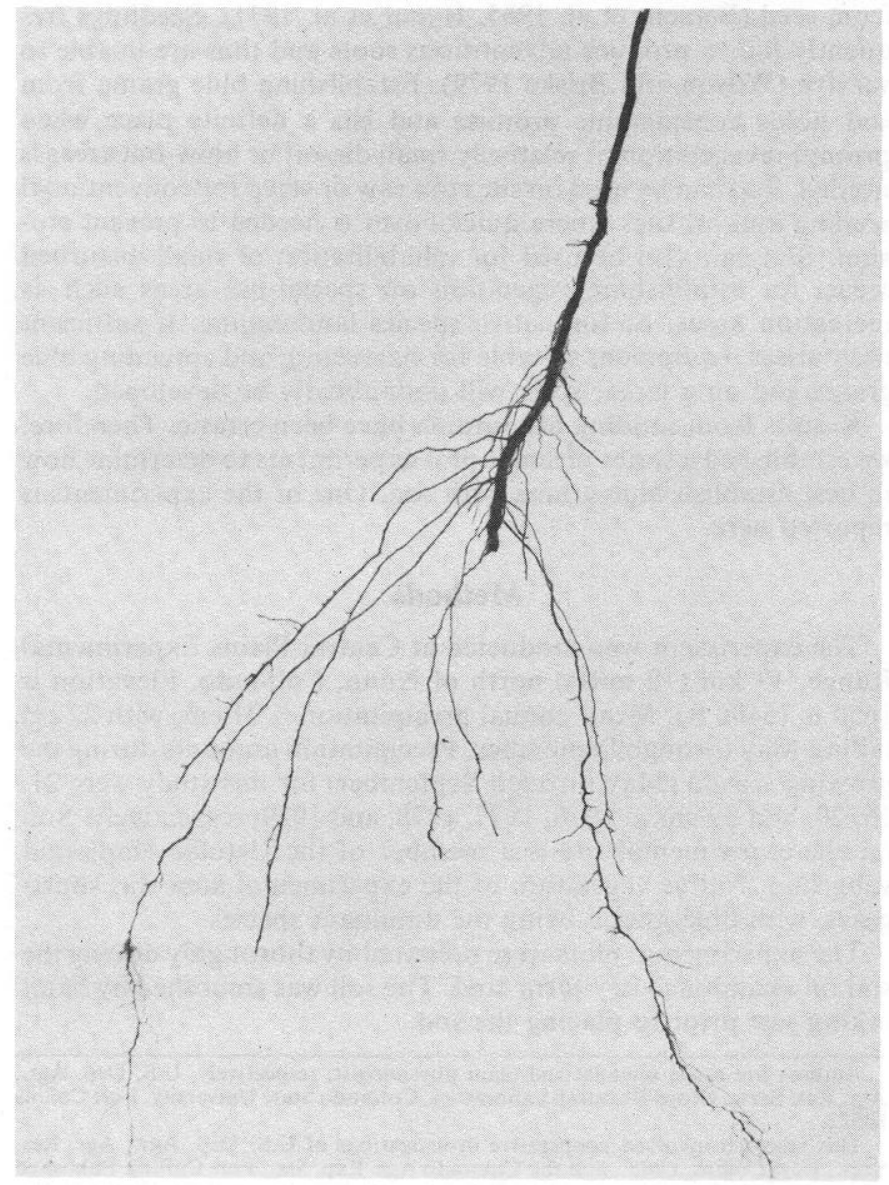

Fig. 2. Development of branch roots from near the distal end of a cut-off adventitios root. Sod was planted June 21, 1977, and then irrigated three times. These branch roots generally occurred on roots from recent tillers. 
Table 2. Number of live tillers/core, number of new adventitious roots/core, rate of adventitious root elongation, and total length of adventitious roots per core for four 1977 dates-of-transplanting and two levels of post-transplanting irrigation.

\begin{tabular}{llcc}
\hline \hline $\begin{array}{l}\text { Factor measured and } \\
\text { date transplanted }\end{array}$ & \multicolumn{3}{c}{ Number of irrigations after planting } \\
\cline { 2 - 4 } Number of tillers & 0 & 1 & 3 \\
$\quad$ May 3 & 52.8 & $47.2^{1}$ & 50.4 \\
June 21 & - & 38.8 & 44.2 \\
July 27 & - & 34.4 & 41.6 \\
August 23 & - & 17.4 & 26.0 \\
Number of adventitious roots & & & \\
May 3 & 5.8 & 8.0 & 15.6 \\
June 21 & - & 9.4 & 13.4 \\
July 27 & - & 2.6 & 3.4 \\
August 23 & - & 1.2 & 8.2 \\
Rate of adventitious root & & & \\
elongation (cm/day) & & & \\
May 3 & 0.7 & 1.0 & 1.2 \\
June 21 & - & 1.2 & 1.8 \\
July 27 & - & 1.3 & 1.9 \\
August 23 & - & 1.2 & 1.3 \\
Total length adventitious & & & \\
roots per core (cm) & & & \\
May 3 & 46 & 63 & 140 \\
June 21 & - & 120 & 257 \\
July 27 & - & 48 & 69 \\
August 23 & - & 21 & 134 \\
\hline
\end{tabular}

'Planting date significantly affected number of surviving tillers, number of adventitious roots, and total length of adventitious roots; number of irrigations significantly affected number of adventitious roots, rate of adventitious root elongation, and total length of adventitious roots $(R<0.05)$. These observations were made 15 to 17 days after planting of sod.

date than on other dates.

Percent stand rating was correlated with the amount of moisture in the soil on which the sod was laid $(r=0.76)$. Both percent stand and percent soil moisture declined as the season progressed. Thus, it was not possible to determine from the available data if soil moisture was the soil factor affecting stand establishment.

The amount of moisture in the sod was also related to sod establishment $(r=0.67)$. The importance of moisture in the sod appeared to be primarily related to keeping the soil in contact with the roots while lifting, transporting, and laying the sod. Pre- wetting the sod at those times when it was dry increased percent stand rating greatly; in fact, for some dates of transplanting, prewetting made the difference between success and failure (Table 1). Sod that had been pre-wet was also much easier to cut and handle. If the sod contained adequate moisture, as it did on August 3, 1976, and July 27,1977 , there would probably be no benefit derived from pre-wetting.

Irrigation of the sod after transplanting was usually necessary for successful establishment. For all dates of transplanting, there were only two successes (a stand rating of $50 \%$ or higher) for the nonirrigated treatment, but with three irrigations, nine soddings were successful (Table 1). A single irrigation produced seven successes, but average stand rating for all dates with the single irrigation was $45 \%$, whereas it was $59 \%$ for three irrigations. Thus, sod generally should not be transplanted unless it can be irrigated at least once after sodding. However, even pre-wetting and three irrigations will not guarantee success, particularly late in the summer; this can be seen in the case of the August 23, 1977, transplanting (Table 1).

\section{Conclusions}

Blue grama can be successfully established through sodding if certain procedures are followed. Sodding should be done early in the growing season, preferably before July. If the sod is not fairly wet, it should be pre-wet by watering thoroughly the day before cutting. Blue grama sod should be $5 \mathrm{~cm}$ thick so that the pieces of sod will hold together. The sod should be kept flat to prevent the soil from falling away from the roots and the pieces of sod from breaking apart. Sod layers should be inter-leaved with hardboard when they are stacked for transport so that the layers of sod can be readily separated for laying without damaging the sod. After being laid on a prepared area, the sod should be firmed into place with a roller to ensure adequate soil contact. As soon as possible after laying, the sod should be irrigated and, if possible, ir rigated two or more times during the following 5 to 7 days.

\section{Literature Cited}

Bement, R.E., R.D. Barmington, A.C. Everson, L.O. Hylton, Jr., and E.E. Remmenga. 1965. Seeding of abandoned croplands in the Central Great Plains. J. Range Manage. 18:53-58.

Hyder, D.N., A.C. Everson, and R.E. Bement. 1971. Seedling morphology and seeding failures with blue grama. J. Range Manage. 24:287-292.

Wilson, A.M., and D.D. Briske. 1979. Seminal and adventitious root growth of blue grama seedlings on the Central Plains. J. Range Manage. $32: 209-213$ 